\title{
ESTADO DA ARTE DO IMBRÓGLIO DA SUCESSÃO DO CÔNJUGE EM CONCORRÊNCIA COM OS DESCENDENTES
}

\author{
Felipe Quintella Machado de Carvalho ${ }^{1}$ \\ Tereza Cristina Monteiro Mafra ${ }^{2}$
}

\begin{abstract}
Resumo: O Código Civil de 2002 alterou a ordem de vocação hereditária anterior, admitindo a concorrência do cônjuge sobrevivente com os descendentes. As novas regras deixaram margem para divergências, as quais se acentuaram na primeira década de vigência do novo Código. Por meio de pesquisa bibliográfica e jurisprudencial, o presente trabalho, na sequência da uniformização de entendimentos do STJ em 2015 quanto aos regimes de comunhão parcial e de separação convencional, apresenta, completados quinze anos de vigência do Código de 2002, o estado da arte do imbróglio na doutrina e na jurisprudência dos Tribunais estaduais.
\end{abstract}

Palavras-chave: Sucessão hereditária. Cônjuge. Concorrência. Descendentes.

\section{STATE-OF-THE-ART OF THE CONTROVERSY REGARDING THE SUCCESSION OF THE SPOUSE TOGETHER WITH THE DESCENDANTS}

\begin{abstract}
The Civil Code of 2002 altered the previous hereditary vocation order, admiting the succession of the spouse together with the descendants. The new rules left margin for interpretative divergences, which increased in the first decade of the new Code's effect. In the year the $\mathrm{CC} / 02$ commemorates 15 years in effect, this essay presents, by means of research in specialized literature and in judicial decisions, the state-of-the-art of the controversy in opinions of experts and in decisions of the State Courts following the 2015 interpretation of the rules regarding the regimes of partial communion and conventional separation established by STJ.
\end{abstract}

Keywords: Hereditary succession. Spouse. Concurrence. Descendants.

\footnotetext{
${ }^{1}$ Doutor, Mestre e Bacharel em Direito pela UFMG. Coordenador do Curso de Graduação em Direito das Faculdades Milton Campos. Professor dos Cursos de Graduação e de Mestrado em Direito das Faculdades Milton Campos. Professor do Ibmec BH. Email: felipe.quintella@gmail.com.

${ }^{2}$ Doutora, Mestra e Bacharela em Direito pela UFMG. Vice-Diretora do Curso de Graduação em Direito das Faculdades Milton Campos. Professora dos Cursos de Graduação e de Mestrado em Direito das Faculdades Milton Campos. Email: tereza.c.mafra@terra.com.br.
} 


\section{INTRODUÇÃO}

Em 2018 o Código Civil de 2002 completa quinze anos de vigência.

Em matéria de sucessão legítima, o novo Código Civil trouxe muitas inovações, sobretudo no que toca à vocação hereditária e sua ordem. Desde logo se deve esclarecer, não obstante, que o vocábulo inovações, aqui, é usado tão somente com o sentido de aquilo que é novo, sem qualquer conotação positiva, no sentido de avanço, melhoria.

O que há de novo no Código de 2002 em matéria de vocação hereditária, e que, sem medo, é possível apontar como o principal desafio contemporâneo da sucessão legítima, é o estabelecimento das hipóteses de concorrência do cônjuge sobrevivente - que passou a ser herdeiro necessário - com os descendentes, na primeira ordem de vocação hereditária.

Ocorre que, em razão de falhas na redação do dispositivo em que as regras sobre a sucessão concorrente foram estabelecidas, diversos problemas de interpretação - e, consequentemente, de aplicação - surgiram, e causaram toda sorte de dificuldades práticas.

Como se não bastasse, no contexto da discussão da inconstitucionalidade das regras sobre a sucessão do companheiro, o Supremo Tribunal Federal acabou fixando tese de repercussão geral em consequência da qual as regras da sucessão concorrente também passaram a se aplicar aos casos de sucessão de conviventes em união estável.

Dadas as graves divergências de interpretação que se instalaram na primeira década de vigência do Código de 2002, inclusive entre a 3a e a 4a Turmas do Superior Tribunal de Justiça e, até mesmo, dentro da 3a, o STJ, em 2015, uniformizou seu entendimento quanto à concorrência do cônjuge sobrevivente com os descendentes nos casos em que o regime de bens do casamento era o da comunhão parcial, e nos casos em que era o da separação convencional.

Considerando-se a relevância das discussões, convém, no ano em que se completam quinze anos de vigência do Código, apresentar o panorama geral das divergências que se instalaram na doutrina e na jurisprudência, para que as controvérsias possam ser compreendidas.

Ademais, ante a importância dos precedentes dos Tribunais superiores, sobretudo na vigência do Código de Processo Civil de 2015, justifica-se uma pesquisa que verifique o estado atual da questão na jurisprudência dos Tribunais estaduais.

Para tanto, são adequadas as metodologias de pesquisa teórica bibliográfica e jurisprudencial.

Revista de Direito de Família e Sucessão | e-ISSN: 2526-0227 | Porto Alegre | v. 4 | n. 2 | p. 40 - 59 | Jul/Dez. 2018 
Com relação à pesquisa bibliográfica, a opção foi pela consulta a manuais de doutrina publicados entre 2016 e 2018, para atestar, por amostragem, se ainda há autores que prosseguem nas divergências.

Quanto à pesquisa jurisprudencial, conforme descrito na seção em se apresentam os respectivos resultados, a busca foi pelos três principais assuntos controvertidos identificados na pesquisa bibliográfica. A pesquisa foi realizada em dois Tribunais de Justiça estaduais por região, também conforme explicado na seção própria. Quanto aos dois primeiros assuntos polêmicos - a sucessão do cônjuge em concorrência com os descendentes, quando o regime de bens do casamento era o da comunhão parcial, e a sucessão do cônjuge em concorrência com os descendentes, quando o regime de bens do casamento era o da separação convencional —, o recorte temporal foram os anos de 2016 a 2018 (até agosto), tendo em vista a uniformização dos respectivos entendimentos do STJ em 2015. Quanto ao terceiro assunto polêmico - a sucessão do cônjuge em concorrência com os descendentes em casos de fíliação híbrida e o problema do quinhão mínimo, o recorte foi todo o período de vigência do Código de 2002, vez que não há entendimento do STJ sobre o ponto.

Com isso, alcança-se o objetivo de apresentar o estado da arte do imbróglio, o que se considera passo imprescindível para que pesquisas posteriores possam ser adequadamente desenvolvidas.

\section{INOVAÇÃO QUANTO À SUCESSÃO DO CÔNJUGE SOBREVIVENTE NO CÓDIGO DE 2002: A POSSIBILIDADE DE CONCORRÊNCIA COM DESCENDENTES}

Tradicionalmente, em sociedades de cultura similar à brasileira, os descendentes figuram na primeira ordem de vocação hereditária, aplicando-se a regra no sentido de que o grau mais próximo exclui o grau mais remoto. Ou seja, se uma pessoa morre e deixa descendentes, estes o sucederão. Se houver filhos, netos, bisnetos, a preferência será dos filhos, salvo o direito de representação quando houver filhos premortos ou excluídos da sucessão que tenham deixado descendentes.

Na doutrina cristã, Santo Tomás de Aquino sustentou ser de direito natural que os pais acumulassem riquezas para os filhos, que deveriam ser seus herdeiros (LASALA, 1978, p. 41). Autores franceses contemporâneos à codificação seguiram tal linha de pensamento, podendo- se mencionar Tronchet, Laurent e Troplong (LASALA, 1978, p. 41). 
No Brasil, Itabaiana de Oliveira menciona corrente desenvolvida por D'Aguano, que fundamenta a sucessão mortis causa em razões biológicas, que conduziriam à continuidade da vida por meio da transmissão de ascendentes a descendentes, não só das características genéticas, mas também psicológicas, concluindo que a lei, ao permitir a transmissão patrimonial, o faz em homenagem a tal continuidade biopsíquica (OLIVEIRA, 1936, p. 44).

Mais tarde, segundo Carlos Maximiliano, além da hereditariedade, acrescentaram-se novos fundamentos, como "a simpatia, o afeto, espontâneo, constante, resolvendo-se em atração recíproca entre indivíduos: tudo consequência da comunidade de sangue, tendências e inclinações, bem como da vida em comum” (MAXILIMILIANO, 1942, p. 22-23).

O Código Civil de 2002, todavia, preocupado com a situação do cônjuge desde o advento da Lei do Divórcio, a qual instituiu o regime de comunhão parcial de bens como regra, alçou-o à condição de herdeiro necessário (art. 1.845), e passou a admitir a concorrência do cônjuge supérstite com os descendentes, na primeira ordem de vocação hereditária (art. 1.829, I), bem como com os ascendentes, na segunda (art. 1.829, II). Com isso, o cônjuge, que até então somente era chamado à sucessão na falta de descendentes e de ascendentes do autor da herança, figurando na terceira ordem de vocação hereditária, encontrou espaço nas duas primeiras, em concorrência com os descendentes ou com os ascendentes.

Trata-se de medida altamente inovadora, que precisava ser implementada com a melhor técnica legislativa possível, até mesmo pela falta de parâmetros no Direito anterior para sua compreensão devida. Todavia, lamentavelmente, uma das falhas mais graves do Código Civil de 2002 é a má técnica legislativa, em especial no livro do Direito das Sucessões.

Quanto à concorrência com os ascendentes, que depende apenas da capacidade para suceder, aferível por meio das regras do art. 1.830, não há dificuldades hermenêuticas.

Todavia, quanto à concorrência com os descendentes, que ficou condicionada ao regime de bens do casamento, a infelicidade na redação das regras no inciso I do art. 1.829 foi tamanha que várias correntes divergentes apareceram na primeira década de vigência do novo Código, como se verá na seção 4.

Nesse sentido, Silvio Venosa, com muito acerto, sugere que, diante de tantas “impropriedades" em partes do Livro V da Parte Especial do Código Civil de 2002, que representam uma "verdadeira tragédia, um desprestígio e um desrespeito para nosso meio jurídico e para a sociedade", "melhor seria que fosse, nesse aspecto, totalmente reescrito e que 
se apagasse o que foi feito, como uma mancha na cultura jurídica nacional" (VENOSA, 2017, p. 146).

\section{ESCLARECIMENTOS PRELIMINARES SOBRE A SUCESSÃO DO CÔNJUGE EM GERAL}

Antes de se iniciar o exame das regras sobre a concorrência do cônjuge sobrevivente com os descendentes e as respectivas divergências de interpretação, no entanto, é preciso assentar dois pilares fundamentais acerca da sucessão do cônjuge em geral: a distinção entre herança e meação, bem como o direito sucessório do cônjuge, dependente de sua capacidade para suceder.

\subsection{COMUNICAÇÃO DE BENS INTER VIVOS E MORTIS CAUSA: DIFERENÇA ENTRE MEAÇÃO E HERANÇA}

O casamento envolve aspectos ligados a interesses patrimoniais comuns a ambos os cônjuges e também interfere em certos negócios realizados com terceiros, em decorrência de um estatuto jurídico especial, que disciplina as relações econômicas dos casados, denominado regime de bens (MADALENO, 2017, p. 704).

Para Pereira Coelho, "a comunhão de vida entre os cônjuges exige um regime particular, mal se concebendo que as relações patrimoniais derivadas do casamento ficassem sujeitas ao regime geral das relações jurídicas obrigacionais ou reais" (COELHO, 1986, p. 446).

Cuida-se, como explica Colomer, de "um conjunto de regras, mais ou menos numerosas e mais ou menos complexas, cuja finalidade é conferir, no aspecto patrimonial, um estatuto particular aos cônjuges a respeito de suas relações mútuas e de suas relações com terceiros" (COLOMER, 1992, p. 2).

O Direito de Família "determina um complexo de modificações importantes nos princípios gerais que regulam o direito de propriedade" (PEREIRA, 1889, p. 88). A incidência dos direitos patrimoniais conjugais promove uma modificação no patrimônio da pessoa casada, de modo que surgem três massas patrimoniais distintas, qualquer que seja o regime de bens do casamento: o conjunto de bens pertencentes somente ao marido (bens particulares, próprios ou exclusivos do marido), o acervo composto pelos bens pertencentes 
somente à mulher (bens particulares, próprios ou exclusivos da mulher) e o aglomerado patrimonial formado pelos bens partilháveis (bens comuns).

De outro lado, conforme disposto no art. 1.784 do Código Civil, "aberta a sucessão, a herança transmite-se, desde logo, aos herdeiros legítimos e testamentários".

O vocábulo herança envolve a integralidade do patrimônio do falecido, uma universalidade de direito, que abrange todas as relações jurídicas de valor econômico relacionadas ao morto (VELOSO, 2003, p. 1596). De acordo com Carlos Roberto Gonçalves, a herança inclui bens, dívidas, créditos, débitos, direitos e obrigações, pretensões e ações de que era titular o falecido, e as que contra ele foram propostas, desde que transmissíveis (GONÇALVES, 2012, p. 32).

É imprescindível destacar que herança não se confunde com meação.

Se, em razão do regime de bens do casamento, há patrimônio comum, ou seja, aquele que pertence em comunhão a ambos os cônjuges, com a morte de um, extingue-se a comunhão, e o sobrevivente faz jus à sua meação, a qual, frise-se, sempre lhe pertenceu. Não há, ali, aquisição por sucessão hereditária.

Quando se fala em sucessão de pessoa que faleceu casada e que deixou patrimônio em comunhão com o sobrevivente, o alcance, sejam quem forem os herdeiros, é apenas à meação do morto.

Por conseguinte, se havia patrimônio comum, e o cônjuge supérstite é chamado à sucessão, além de ficar com a sua meação (ele não a recebe, pois sempre a teve), o cônjuge adquire a totalidade ou parte da meação do morto.

É como bem esclarece J. M. Leoni Lopes de Oliveira: “a meação do cônjuge ou companheiro não decorre do fato jurídico morte. A meação do cônjuge decorre do regime de bens do casamento ou da união estável” (OLIVEIRA, 2018, p. 371).

\subsection{DIREITO SUCESSÓRIO DO CÔNJUGE - CAPACIDADE OU LEGITIMIDADE PARA SUCEDER}

No sistema do Código de 2002, seja em concorrência com os descendentes, seja com os ascendentes, ou sozinho, ao cônjuge só se atribui direito sucessório, nos termos do art. 1.830 , "se, ao tempo da morte do outro, não estavam separados judicialmente, nem separados de fato há mais de dois anos, salvo prova, neste caso, de que essa convivência se tornara impossível sem culpa do sobrevivente". 
A despeito de toda a crítica nos últimos tempos à análise da culpa no Direito de Família, o "novo-velho" Código Civil de 2002 - que, apesar de promulgado no século XXI, foi praticamente todo concebido e gestado na década de 1970 - consagrou a perquirição de culpa no Direito das Sucessões.

No sistema adotado, então, se o casal não estava separado ao tempo da morte de um dos cônjuges, terá o outro direito sucessório; se estavam separados judicialmente, não haverá direito sucessório; se estavam separados de fato há menos de dois anos, não importa por qual motivo, haverá direito sucessório; se, por sua vez, estavam separados há mais de dois anos, em razão de fato imputável ao cônjuge sobrevivente, não haverá direito sucessório; se, por fim, estavam separados há mais de dois anos, em razão de fato imputável ao cônjuge falecido, haverá direito sucessório.

A confusão se encontra esquematizada a seguir:

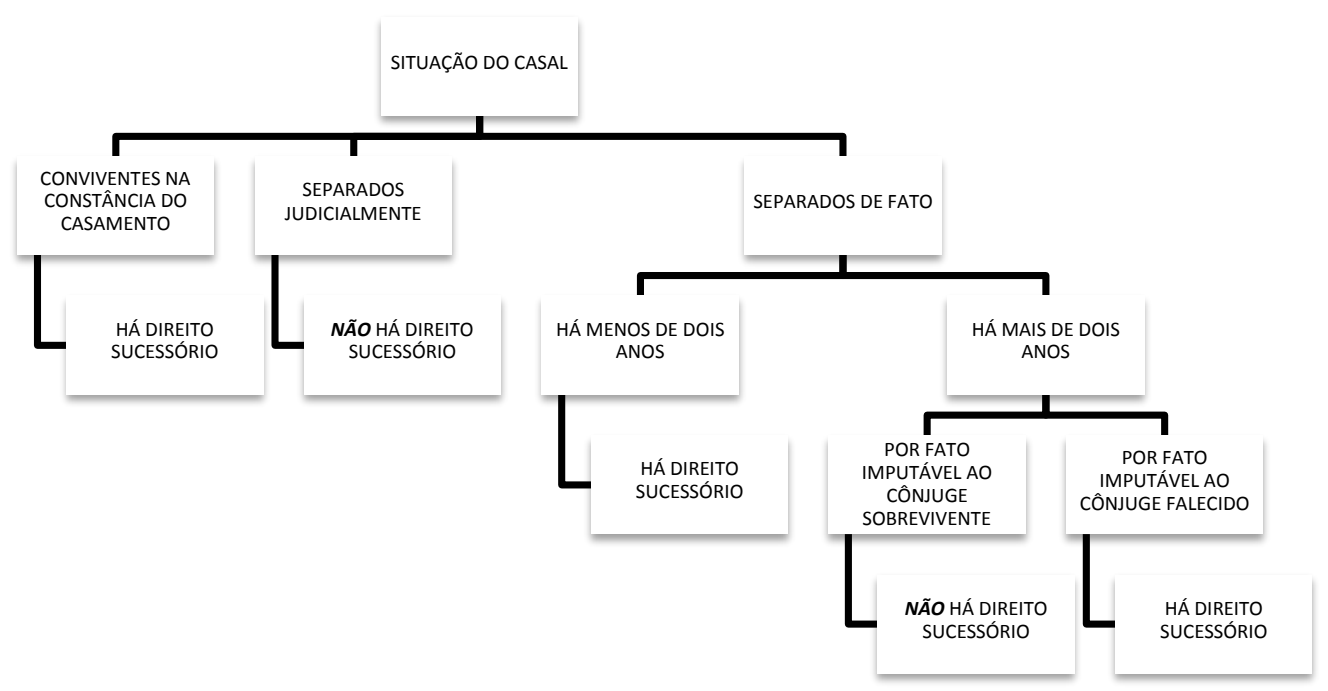

Figura 1 - Esquema de interpretação do art. 1.830 do Código Civil.

Isso, é claro, se ainda for admitida, no caso concreto, a discussão de culpa. A tendência na doutrina é de os autores rechaçarem a possibilidade da controvertida discussão. 


\section{AS REGRAS SOBRE A CONCORRÊNCIA DO CÔNJUGE COM DESCENDENTES E AS RESPECTIVAS DIVERGÊNCIAS DE INTERPRETAÇÃO}

Assentadas as bases examinadas na seção anterior, passa-se agora à análise das regras sobre a concorrência do cônjuge com descendentes e das respectivas divergências de interpretação.

Aqui, cabe esclarecer que foram consultadas as obras de doutrina de Arnaldo Rizzardo (2018), César Fiuza (2016), Elpídio Donizetti e Felipe Quintella (2018), Flávio Tartuce (2018), J. M. Leoni Lopes de Oliveira (2018), Luiz Paulo Vieira de Carvalho (2017), Pablo Stolze Gagliano e Rodolfo Pamplona Filho (2017), e Salomão Cateb (2015). A ideia foi selecionar obras atualizadas a partir de 2016 de autores de estados variados. O livro de Salomão Cateb, cuja última edição foi publicada em 2015, foi utilizado em razão de um posicionamento peculiar do autor sobre assunto ainda não debatido pelo STJ.

Pois bem. Conforme o art. 1.829, I do Código de 2002, a sucessão defere-se "aos descendentes, em concorrência com o cônjuge sobrevivente, salvo se casado este com o falecido no regime da comunhão universal, ou no da separação obrigatória de bens (art. 1.640, parágrafo único); ou se, no regime da comunhão parcial, o autor da herança não houver deixado bens particulares".

Como se vê, a concorrência ou não do cônjuge supérstite com os descendentes depende do regime de bens do casamento.

É seguro afirmar que há unanimidade de interpretação das referidas regras apenas com relação a dois regimes: o da comunhão universal e o da separação obrigatória de bens. Sendo um destes o regime de bens do casamento, o cônjuge sobrevivente não concorrerá com os descendentes. Com relação aos demais regimes - comunhão parcial, separação convencional (absoluta) e participação final nos aquestos - há controvérsias. E muitas.

\subsection{REGIME DE COMUNHÃO PARCIAL DE BENS}

Se o falecido era casado pelo regime da comunhão parcial de bens, primeiramente, por interpretação literal do art. 1.829, I, é preciso verificar se deixou ou não patrimônio particular, pois a sua existência, ou não, condiciona o direito do cônjuge sobrevivente.

Para a grande maioria dos autores, o direito à concorrência do cônjuge depende da existência de patrimônio particular (TARTUCE, 2018, p. 176; VENOSA, 2018, p. 161;

Revista de Direito de Família e Sucessão | e-ISSN: 2526-0227 | Porto Alegre | v. 4 | n. 2 | p. 40 - 59 | Jul/Dez. 2018 
RIZZARDO, 2018, p. 183; DONIZETTI et QUINTELLA, 2018, p. 1139; CARVALHO, 2017, p. 361; GAGLIANO et PAMPLONA, 2017, p. 1513; FIUZA, 2016, p. 1294). Isso porque a inexistência de bens particulares parece ser a última hipótese de exceção ao direito à concorrência do cônjuge, na parte final do art. 1.829, I.

Para Maria Berenice Dias, não obstante, só haverá direito à concorrência se não houver patrimônio particular. Em um pequeno artigo intitulado Ponto-e-vírgula, a autora destaca o uso do sinal de pontuação que separa a referência aos regimes de comunhão parcial e de separação obrigatória da referência ao regime de comunhão parcial (DIAS, 2003). O ponto-e-vírgula utilizado interromperia as exceções enumeradas após o "salvo se" no início do texto. Por conseguinte, a leitura correta seria que se defere a sucessão "aos descendentes, em concorrência com o cônjuge sobrevivente, (...) se, no regime da comunhão parcial, o autor da herança não houver deixado bens particulares".

Apesar de embasado na aplicação do método literal de interpretação, esse entendimento não alcançou maioria na doutrina. Isso porque, por aplicação do método lógico, a conclusão é a de que após estabelecer a regra geral da concorrência, o Código enumerou as hipóteses de exceção, baseadas nos regimes de bens.

E a divergência não parou por aí. Ainda apareceu uma terceira interpretação da norma. Atuando como ministro convocado no STJ, Honildo Amaral de Mello Castro, desembargador do TJAP, argumentou que o cônjuge só deveria ser herdeiro quando não for meeiro, e, por conseguinte, no caso da comunhão parcial, só deveria concorrer com os descendentes quando não houver patrimônio comum, ou seja, quando o autor da herança houver deixado apenas patrimônio particular (STJ, REsp 974.241/DF, Quarta Turma, relator: Min. HONILDO AMARAL DE MELLO CASTRO — DESEMBARGADOR CONVOCADO DO TJ/AP relatora p/ Acórdão: Min. MARIA ISABEL GALLOTTI, julgado em 07/06/2011, DJe 05/10/2011).

Por fim, caso seja adotado o entendimento majoritário, em se tratando de regime de comunhão parcial de bens, ainda há outra questão a se considerar: havendo direito à concorrência, o cônjuge sucede (1) na totalidade da herança, (2) apenas na meação do morto no patrimônio comum, ou (3) apenas no patrimônio particular do falecido? Em que esfera patrimonial, afinal, sucede o cônjuge?

Muitos autores concordam que, se o direito à concorrência fica condicionado à existência de patrimônio particular - pois seguem esse posicionamento -, a sucessão do cônjuge somente deve ocorrer nesta parte da herança (OLIVEIRA, 2018, p. 330; TARTUCE, 
2018, p. 176; DONIZETTI et QUINTELLA, 2018, p. 1139; GAGLIANO et PAMPLONA, 2017, p. 1513; FIUZA, 2016, p. 1294). Neste caso, apenas os descendentes herdariam a meação do morto no patrimônio comum. Mais uma vez, há recurso ao método lógico de interpretação.

Outros autores, por sua vez, valendo-se da regra hermenêutica que determina que, quando a lei não distingue, não cabe ao intérprete distinguir, sugerem que o cônjuge deve concorrer com os descendentes na totalidade da herança (RIZZARDO, 2018, p. 183).

Uma terceira corrente, ademais, surgiu no âmbito do STJ, em julgado relatado pela Min. Nancy Andrighi, no sentido de que o cônjuge somente herda uma fração da meação do morto no patrimônio particular (STJ, REsp 1377084/MG, Terceira Turma, relatora: Min. NANCY ANDRIGHI, julgado em 08/10/2013, DJe 15/10/2013). Em síntese, o argumento é no sentido de que se deve preservar a vontade do casal que, em vida, optou por excluir do patrimônio particular o outro cônjuge, e somente dividir o patrimônio comum. Também com a morte, pois, deveria ser restringido o acesso do sobrevivente ao patrimônio particular do falecido, que seria todo devolvido aos descendentes.

Há bons argumentos para sustentar todos os três diferentes posicionamentos.

O imbróglio, então, tornou-se insustentável.

Em 2015, pois, a Segunda Seção do STJ uniformizou o entendimento do Tribunal quanto às controvérsias sobre a comunhão parcial, no sentido de que o cônjuge só concorre quando houver patrimônio particular, e apenas concorre no patrimônio particular (STJ, REsp 1368123/SP, Segunda Seção, relator: Min. SIDNEI BENETI, relator p/ Acórdão: Min. RAUL ARAÚJO, julgado em 22/04/2015, DJe 08/06/2015).

O posicionamento do STJ acabou sendo o mesmo outrora firmado no enunciado no 270 da III Jornada de Direito Civil promovida pelo Conselho da Justiça Federal.

\subsection{REGIMES DE SEPARAÇÃO DE BENS}

A leitura do art. 1.829, I leva a crer que somente não haverá concorrência do cônjuge sobrevivente com os descendentes em caso de separação de bens se o regime for de separação obrigatória, ou seja, legal.

Aparentemente, para evitar dúvidas, considerando-se a variedade de expressões utilizadas para referência aos regimes de separação - separação obrigatória, separação legal, separação convencional, separação absoluta, separação total -, o texto faz remissão ao art.

Revista de Direito de Família e Sucessão | e-ISSN: 2526-0227 | Porto Alegre | v. 4 | n. 2 | p. 40 - 59 | Jul/Dez. 2018 
1.640, parágrafo único. Mas eis que há aqui mais um problema de técnica legislativa. $\mathrm{O}$ dispositivo citado cuida da possibilidade de escolha de regime de bens pelos nubentes, e não de qualquer regime de separação. A referência, acredita-se, deveria ser ao art. 1.641, o qual enumera as hipóteses em que se impõe o regime de separação - e que, por isso, recebe os adjetivos obrigatória ou legal.

Sendo assim, haveria concorrência quando o regime de bens do casamento for o da separação convencional ou absoluta, quer dizer, aquele que não é imposto pela lei, mas escolhido pelos nubentes (nesse sentido: TARTUCE, 2018, p. 180; VENOSA, 2018, p. 168; RIZZARDO, 2018, p. 184; DONIZETTI et QUINTELLA, 2018, p. 1138; CARVALHO, 2017, p. 345; GAGLIANO et PAMPLONA, 2017, p. 1519; FIUZA, 2016, p. 1294).

Ocorre que, a princípio, a ideia de que o cônjuge casado por regime de separação convencional concorreria com os descendentes na sucessão do cônjuge falecido arrepiou a comunidade jurídica, até mesmo o presidente da comissão responsável pela elaboração do anteprojeto do Código.

Miguel Reale publicou online, então, um pequeno artigo em que discute a questão e, pretendendo valer-se de interpretação sistemática, sugere que (REALE):

\begin{abstract}
(...) duas são as hipóteses de separação obrigatória: uma delas é a prevista no parágrafo único do Art. 1.641, abrangendo vários casos; a outra resulta da estipulação feita pelos nubentes, antes do casamento, optando pela separação de bens.

A obrigatoriedade da separação de bens é uma consequência necessária do pacto concluído pelos nubentes, não sendo a expressão "separação obrigatória" aplicável somente nos casos relacionados no parágrafo único do Art. 1.641.

Essa minha conclusão ainda mais se impõe, ao verificarmos que - se o cônjuge casado no regime de separação de bens fosse considerado herdeiro necessário do autor da herança - estaríamos ferindo substancialmente o disposto no Art. 1.687, sem o qual desapareceria todo o regime de separação de bens, em virtude de conflito inadmissível entre esse artigo e o de $n^{\circ}$ 1.828, I, fato que jamais poderá ocorrer em uma codificação, à qual é inerente o princípio da unidade sistemática.
\end{abstract}

De início já se percebe a confusão constante com os números. As hipóteses em que a lei impõe o regime de separação de bens estão enumeradas no art. 1.641, caput. Nem estão no parágrafo único do art. 1.640, nem no do art. 1.641, que sequer tem parágrafos. E a ordem de vocação hereditária está estabelecida no art. 1.829, não no 1.828 .

Em segundo lugar, interpretação sistemática é a que se vale de elementos do texto objeto de interpretação e dos demais elementos do sistema em que ele se insere, e que 
guardam uma relação de coerência. Todavia, não parece ser o caso. O "sistema" do Código não permite concluir que o regime de separação livremente escolhido pelos nubentes merecesse o adjetivo obrigatória, nem em seu sistema o Código se refere a esse regime como tal. Estabelece que é obrigatório o regime da separação apenas no caput do art. 1.641, em que estão enumeradas as hipóteses em que o regime é imposto pela lei, e não escolhido pelos nubentes.

Não obstante, apesar dessas falhas hermenêuticas, a proposta de Miguel Reale chegou a ser acolhida pelo STJ (STJ, REsp 992.749/MS, Terceira Turma, relatora: Min. NANCY ANDRIGHI, julgado em 01/12/2009, DJe 05/02/2010).

Instalou-se, pois, a controvérsia: conforme uma corrente, o cônjuge casado com o falecido pelo regime de separação convencional concorreria com os descendentes do autor da herança; segundo outra corrente, o regime de separação convencional, assim como o da separação legal, impediria a concorrência.

Também quanto a esta peleja, a Segunda Seção do STJ uniformizou o entendimento do Tribunal em 2015, no sentido de que o regime da separação convencional de bens não se encontra entre as exceções à concorrência previstas no art. 1.829, I; logo, o cônjuge casado por tal regime concorre com os descendentes (STJ, REsp 1382170/SP, Segunda Seção, relator: Min. MOURA RIBEIRO, relator p/ Acórdão: Min. JOÃO OTÁVIO DE NORONHA, julgado em 22/04/2015, DJe 26/05/2015).

Também aqui, o posicionamento do Tribunal acabou sendo no mesmo sentido em que anteriormente fora estabelecido o enunciado no 270 da III Jornada de Direito Civil promovida pelo Conselho da Justiça Federal.

\subsection{REGIME DE PARTICIPAÇÃO FINAL NOS AQUESTOS}

Com relação ao regime da participação final nos aquestos, inicialmente, não era de se esperar controvérsia. Afinal, o art. 1.829, I nada determinou sobre este regime entre as exceções à regra geral da concorrência do cônjuge supérstite com os descendentes.

Todavia, na tentativa de melhorar o caos hermenêutico que se estabeleceu acerca do art. 1.829, I, foi aprovado, na III Jornada de Direito Civil promovida pelo Conselho da Justiça Federal em parceria com o STJ, o já mencionado enunciado no 270, com o seguinte conteúdo: “o art. 1.829, inc. I, só assegura ao cônjuge sobrevivente o direito de concorrência com os descendentes do autor da herança quando casados no regime da separação convencional de 
bens ou, se casados no regime da comunhão parcial ou participação final nos aquestos, o falecido possuísse bens particulares, hipóteses em que a concorrência se restringe a tais bens, devendo os bens comuns (meação) ser partilhados exclusivamente entre os descendentes".

A partir de então, duas correntes foram identificadas: a que entende que a ausência de referência ao regime entre as exceções leva à aplicação da regra geral e, por conseguinte, à concorrência do cônjuge com os descendentes; a que entende que a concorrência depende da existência de bens particulares do autor da herança.

\subsection{POLÊMICA QUANTO AO DIREITO A QUINHÃO MÍNIMO}

Quem dera a dificuldade quanto à concorrência do cônjuge com os descendentes se encerrasse nas quase instransponíveis divergências acerca dos regimes de bens e das esferas patrimoniais.

Infelizmente, porém, o Código de 2002 criou outra novidade, no art. 1.832, igualmente sem atentar à boa técnica legislativa.

Segundo o art. 1.832, “em concorrência com os descendentes (art. 1.829, inciso I) caberá ao cônjuge quinhão igual ao dos que sucederem por cabeça, não podendo a sua quota ser inferior à quarta parte da herança, se for ascendente dos herdeiros com que concorrer”. Trata-se do chamado quinhão mínimo do cônjuge.

Nos termos do art. 1.832, se o cônjuge for chamado à sucessão em concorrência com descendentes seus, receberá, no mínimo, um quarto da herança. Por exemplo, se concorrer com quatro filhos seus com o falecido, receberá um quarto da herança, e os filhos partilharão os restantes três quartos, recebendo, pois, três dezesseis avos cada.

Por interpretação a contrario sensu, se o cônjuge for chamado à sucessão em concorrência com descendentes tão somente do autor da herança, não fará jus a quinhão mínimo. Se, então, concorrer com quatro filhos do falecido, receberá um quinto da herança, assim como todos os demais.

Ocorre que o legislador se olvidou de disciplinar uma hipótese bastante comum: aquela em que o cônjuge é chamado à sucessão em concorrência tanto com descendentes exclusivos do autor da herança quanto com descendentes que teve com ele. Por exemplo, o falecido deixou dois filhos do primeiro casamento e, com a viúva, sua segunda esposa, teve mais três. 
Não há solução na lei para essa hipótese - a que a doutrina passou a se referir como caso de filiação híbrida —, o que, então, gerou três correntes para resolvê-la.

Segundo a primeira corrente, considerando-se o silêncio da lei, bem como o fato de que a primeira ordem é a dos descendentes, deve-se aplicar a interpretação que lhes seja menos desfavorável. Ou seja, na dúvida, não se atribui ao cônjuge quinhão mínimo (OLIVEIRA, 2018, p. 339; TARTUCE, 2018, p. 186; DONIZETTI et QUINTELLA, 2018, p. 1145).

Para a segunda corrente, deve-se levar em conta o fato de que o Código de 2002 privilegiou a sucessão do cônjuge, que antes figurava na terceira ordem de vocação hereditária, como herdeiro legítimo, e alçou-o à posição de herdeiro necessário, com direito a concorrer com descendentes ou ascendentes, nas duas primeiras ordens. Por essa razão, na dúvida, aplica-se a interpretação que lhe for mais favorável, e se lhe atribui o quinhão mínimo (VENOSA, 2017, p. 149).

Uma terceira corrente, por sua vez, propõe o desenvolvimento de uma solução matemática que encontrasse uma fórmula para o cálculo do quinhão do cônjuge que preservasse seu direito ao quinhão mínimo com relação aos descendentes comuns, mas que não o conferisse com relação aos descendentes exclusivos do falecido (CATEB, 2015, p. 120).

A dificuldade, nesse caso, além do cálculo da fórmula, é que herdeiros da mesma classe e do mesmo grau receberiam quinhões diferentes, simplesmente porque uns descendem do cônjuge sobrevivente do falecido e outros não. A solução afronta o princípio da igualdade, e, por conseguinte, revela-se inconstitucional.

Na tentativa de contribuir para a solução da questão, foi aprovado, na V Jornada de Direito Civil promovida pelo Conselho da Justiça Federal em parceria com o STJ, o enunciado no 527, com o seguinte conteúdo: "Na concorrência entre o cônjuge e os herdeiros do de cujus, não será reservada a quarta parte da herança para o sobrevivente no caso de filiação híbrida". 


\section{POSICIONAMENTOS JURISPRUDENCIAIS SOBRE A SUCESSÃO DO CÔNJUGE APÓS QUINZE ANOS DE VIGÊNCIA DAS REGRAS DO CÓDIGO DE 2002}

Passados quinze anos da entrada em vigor do Código Civil de 2002, justifica-se pesquisa jurisprudencial que verifique como vêm se posicionando os Tribunais estaduais. Ademais, convém verificar se, quanto às polêmicas sobre as quais o STJ uniformizou seus entendimentos em 2015, os Tribunais estaduais vêm seguindo tais entendimentos.

Para tanto, por meio da metodologia de investigação jurisprudencial, foram pesquisados os seguintes assuntos: (1) sucessão do cônjuge em concorrência com os descendentes, quando o regime de bens do casamento era o da comunhão parcial; (2) sucessão do cônjuge em concorrência com os descendentes, quando o regime de bens do casamento era o da separação convencional; (3) sucessão do cônjuge em concorrência com os descendentes em casos de filiação híbrida.

Para obter resultados mais abrangentes, a pesquisa foi realizada em dois Tribunais por região. Quanto à região sudeste, optou-se pelo TJSP e pelo TJMG; quanto à região sul, optouse pelo TJRS e pelo TJPR; quanto à região nordeste, pelo TJPE e pelo TJBA; quanto à região norte, pelo TJAM e pelo TJRO; por fim, quanto à região centro-oeste, a opção foi pelo TJDF e pelo TJMT.

Quanto aos dois primeiros assuntos da pesquisa, considerando-se que a uniformização de entendimentos pelo STJ ocorreu em 2015, o recorte temporal foram os anos de 2016, 2017 e 2018 (até agosto). Quanto ao terceiro assunto, foram pesquisados os quinze anos de vigência do Código.

Os resultados foram organizados nas subseções a seguir.

\subsection{JURISPRUDÊNCIA DOS TRIBUNAIS ACERCA DA CONCORRÊNCIA DO CÔNJUGE COM DESCENDENTES EM CASO DE REGIME DE COMUNHÃO PARCIAL DE BENS}

Quanto à concorrência do cônjuge com descendentes quando o regime de bens do casamento era o da comunhão parcial, no período entre 2016 e agosto de 2018, foram encontrados 23 julgados no TJSP; 2 no TJMG; 1 no TJRS; 1 no TJDF; 1 no TJPE; 1 no 
TJAM e 1 no TJRO. No TJPR, no TJMT e no TJAM não foram encontrados julgados sobre o assunto no período. No total, pois, foram encontrados 30 julgados.

Para a pesquisa foram utilizadas as seguintes palavras-chave: sucessão, cônjuge, descendentes, concorrência, "regime de bens" e "comunhão parcial".

Dos 30 julgados encontrados, 28 seguem o entendimento do STJ, seja com referência direta, seja por coincidência, ou por referência ao enunciado no 270 da III Jornada de Direito Civil.

Apenas dois julgados, ambos de 2016, e ambos do TJSP, utilizaram posicionamento diverso ao do STJ (TJSP, Agravo de Instrumento 2252765-08.2015.8.26.0000, Relator (a): Mary Grün; Órgão Julgador: $7^{\mathrm{a}}$ Câmara de Direito Privado; Foro de Botucatu - $2^{\mathrm{a}}$ Vara Cível, Data do Julgamento: 30/03/2016, Data de Registro: 30/03/2016; TJSP, Agravo de Instrumento 2262656-53.2015.8.26.0000, Relator (a):Paulo Alcides, Órgão Julgador: $6^{\text {a }}$ Câmara de Direito Privado, Foro de Brodowski - Vara Única, Data do Julgamento: 02/06/2016, Data de Registro: 02/06/2016).

Interessante observar que, no caso do Agravo de Instrumento 225276508.2015.8.26.0000, o acórdão dialoga com o julgado da Segunda Seção do STJ em que se uniformizou o posicionamento do Tribunal; não obstante, na interpretação da relatora, no julgado do TJSP, a interpretação da decisão do STJ comporta exceções (p. 7 do acórdão).

Quanto ao Agravo de Instrumento 2262656-53.2015.8.26.0000, o acórdão desconsiderou o julgado da Segunda Seção do STJ e apresentou como precedentes o REsp $n^{\circ}$ 1.377.084, relatado pela Min. Nancy Andrighi em 2013, bem como um julgado da $6^{\mathrm{a}}$ Câmara Cível do TJSP.

\subsection{JURISPRUDÊNCIA DOS TRIBUNAIS ACERCA DA CONCORRÊNCIA DO CÔNJUGE COM DESCENDENTES EM CASO DE REGIME DE SEPARAÇÃO CONVENCIONAL DE BENS}

Quanto à concorrência do cônjuge com descendentes quando o regime de bens do casamento era o da separação convencional, no período entre 2016 e agosto de 2018, foram encontrados 8 julgados no TJSP; 1 no TJMG; 2 no TJRS; 2 no TJPR; 1 no TJDF e 1 no TJPE. No TJBA, no TJAM, no TJRO e no TJMT não foram encontrados julgados sobre o assunto no período. 
Para a pesquisa foram utilizadas as seguintes palavras-chave: sucessão, cônjuge, descendentes, concorrência, "regime de bens" e "separação convencional".

Dos 15 julgados encontrados, todos seguiram o entendimento uniformizado pelo STJ em 2015.

\subsection{JURISPRUDÊNCIA DOS TRIBUNAIS ACERCA DA CONCORRÊNCIA DO CÔNJUGE COM DESCENDENTES EM CASO DE FILIAÇÃO HÍBRIDA}

Não foi encontrado julgado que tratasse especificamente da controvérsia acerca do quinhão mínimo do cônjuge nos casos de filiação híbrida em qualquer dos dez Tribunais estaduais originalmente selecionados, mesmo com o amplo recorte temporal (2003-2018).

Para a pesquisa foram utilizadas as seguintes palavras-chave: sucessão, cônjuge, descendentes, concorrência, quinhão.

Fazendo-se pesquisa livre, todavia, foram encontrados três julgados sobre a polêmica: um no TJMT, outro no TJTO, e outro no TJRJ.

Nos três casos, os Tribunais entenderam que na hipótese em que o cônjuge sobrevivente é chamado à sucessão em concorrência com descendentes comuns e descendentes exclusivos do autor da herança, não se aplica a garantia do quinhão mínimo (TJMT, Agravo de Instrumento 57454/2009, relator: Des. Leônidas Duarte Monteiro, Terceira Câmara de Direito Privado, julgado em 21/10/2009, publicado no DJE 29/10/2009; TJTO, Agravo de Instrumento no 5000741-74.2013.8.27.0000, Turma das Câmaras Cíveis, relator: Desa Celina Regina Regis, julgado em 05/02/2013; TJRJ, Embargos de Declaração em Agravo de Instrumento nº 0062236-95.2014.8.19.0000, Terceira Câmara Cível, relator: Des. Luiz Fernando Ribeiro de Carvalho, julgado em 22/01/2015). 


\section{CONCLUSÃO}

Conclui-se, inicialmente, que é absurda a situação criada pelas regras da sucessão concorrente do cônjuge com os descendentes no Código Civil de 2002. A enorme variedade de entendimentos é assustadora.

E o pior é que, conforme muito bem observa Flávio Tartuce, “a confusão feita não é causada pelas mentes dos doutrinadores e julgadores, que não medem esforços para resolver os problemas que lhe são levados à análise". Prossegue o autor: "a variação perigosa de pensamento jurídico e a miríade de teorias foram geradas pelo legislador, ao fazer a infeliz opção pela concorrência sucessória” (TARTUCE, 2018, p. 177).

O que se verifica, passados quinze anos da entrada em vigor do Código de 2002, é que as divergências que já chegaram ao Superior Tribunal de Justiça — as que dizem respeito à concorrência ou não do cônjuge com os descendentes nos casos de comunhão parcial de bens e de separação convencional - acabaram sendo resolvidas pelo Tribunal em 2015, e que os Tribunais de Justiça dos Estados, desde em então, vêm majoritariamente seguindo os posicionamentos uniformizados pelo STJ.

Em contrapartida, em obras de doutrina publicadas entre 2016 e 2018, ainda há autores que sustentam, não apenas em sede de crítica, mas em sede de interpretação das regras, os posicionamentos rechaçados pelo STJ.

Ademais, uma terceira controvérsia - acerca da atribuição ou não de quinhão mínimo ao cônjuge nos casos de filiação híbrida — não foi ainda objeto de debate significativo em grau recursal nos Tribunais pátrios.

Constata-se, pois, que o imbróglio sobre a sucessão concorrente do cônjuge com os descendentes permanece, e que não se deve deixar de pressionar o legislador — verdadeiro causador das controvérsias - para que reforme as regras em questão. Ainda mais agora, considerando-se que tais regras passam a se aplicar também à união estável.

Oportunidade para reformas legislativas já houve, vez que transcorridos quinze anos de vigência do Código Civil de 2002. É inadmissível - e vergonhoso — que o impasse perdure mais tempo. 


\section{REFERÊNCIAS}

CATEB, Salomão. Direito das Sucessões. 8. ed. São Paulo: Atlas, 2015.

COELHO, Francisco Manuel Pereira. Curso de Direito de Família. Coimbra: Atlântida Editora, 1986.

COLOMER, André. Droit civil: regimes matrimoniaux. 5. éd. Paris: Litec, 1992.

DIAS, Maria Berenice. Ponto-e-vírgula. Jus Navigandi, 2003. Disponível em: <https://jus.com.br/artigos/4177/ponto-e-virgula>. Acesso em: 20 jul. 2018.

DONIZETTI, Elpídio; QUINTELLA, Felipe. Curso Didático de Direito Civil. 7. ed. São Paulo: Atlas, 2018.

FIUZA, César. Direito Civil: curso completo. 18. ed. São Paulo: Revista dos Tribunais, 2016. GAGLIANO, Pablo Stolze; PAMPLONA FILHO, Rodolfo. Manual de Direito Civil. São Paulo: Saraiva, 2017.

GONÇALVES, Carlos Roberto. Direito Civil Brasileiro: Direito das Sucessões. V. 7. 6. ed. São Paulo: Saraiva, 2012.

LASALA, Pérez. Derecho de Sucesiones. V. 1. Buenos Aires: Depalma, 1978.

MAXIMILIANO, Carlos. Direito das Sucessões. V. 1. 2. ed. Rio de Janeiro: Freitas Bastos, 1942.

OLIVEIRA, Arthur Vasco Itabaiana de. Tratado de Direito das Sucessões. V. 1. 3. ed. Rio de Janeiro: Livraria Jacintho Ribeiro dos Santos, 1936.

OLIVEIRA, J. M. Leoni Lopes. Direito Civil: Sucessões. Rio de Janeiro: Forense, 2018. PEREIRA, Lafayette Rodrigues. Direitos de família. 2. tir. Rio de Janeiro: Tipografia da Tribuna Liberal, 1889.

REALE, Miguel. $O$ cônjuge no novo Código Civil. Disponível em: http://miguelreale.com.br/artigos/conjncc.htm. Acesso em: 20 jul. 2018.

RIZZARDO, Arnaldo. Direito das Sucessões. 10. ed. Rio de Janeiro: Forense, 2018.

TARTUCE, Flávio. Direito Civil: Direito das Sucessões. 11. ed. São Paulo: Método, 2018. 
VELOSO, Zeno. Comentários ao Código Civil. (Coord. Antônio Junqueira de Azevedo.) V. 21. São Paulo: Saraiva, 2003.

VENOSA, Silvio de Salvo. Direito Civil: Sucessões.18. ed. São Paulo: Atlas, 2018. 